\title{
Solving the Spatial Relationships in Manufacturing Systems
}

\author{
Naqib Daneshjo ${ }^{1 *}$, Albert Mareš², Erika Dudáš Pajerká \\ 1 Faculty of Business Economics with seat in Kosice, University of Economics in Bratislava, Slovakia \\ 2 Technical university in Košice, Letná 9, 04001 Košice, Slovakia \\ * Corresponding author's e-mail: daneshjo47@gmail.com
}

\begin{abstract}
Markets are already dynamic, and will continue to be so in the future. The pressure of customers / users for substantial product and service customization increases. Therefore, their demands must be met in a highly flexible, responsive and adaptable manner. The structural changes in company manufacturing systems need to be quickly adapted to the changing requirements and responded to in real-time. Production must not only be highly flexible with high-quality services, but it must be ready for work in integrated network structures. A logical response to these demands is the further development of industrial production ready for the changes presented in the forecasts of the fourth industrial revolution. In essence, it is a project of digitalization and sophistication of the industry. The new designs of highly integrated manufacturing systems and their clusters will ensure communication between the people and the means of production, as well as the production systems and other physical objects.
\end{abstract}

Keywords: manufacturing systems, highly flexible, NC machine, industry

\section{INTRODUCTION}

Workstations are production and organizational units, defined by a certain space, equipped with the necessary means of production according to the character of the activities performed, in which complete and closed partial technological, handling, control or other operations take place.

The resulting function of the production process (execution of production tasks) is the unification of partial functions, which are performed at the physical elements (workstations). Using the means of production, the manufacturing process determined by the production program of a production system is carried out. Other subsystems (handling and control) are needed to make the production or the technological subsystem perform the functions specified as efficiently as possible. In terms of meeting the production targets, the workstations integrated in the production system do not have the same structural shape and roles. The production or technological workstations are basic conditions for their activity are created elsewhere. The types and the number of necessary workstations are determined by the technology used and the organization of the material flows [1]. The production process is divided into operations that are subdivided into individual production and time-related parts, which are assigned to the workstations as separate tasks. Each workstation is designed to perform a certain range of operations. Since automation in the production process shifts the human activities to technical elements, in the field of technology, handling and management, the position of a man in the production process changes.

Conventional workstations are those where the worker handles products, semi-finished products or other material objects directly or where the workplace preparation and technological or other processes are carried out through handling equipment and by his direct or indirect action. In the NC machine workstations, the worker handles the semi-products or products directly or indirectly by means of the handling equipment. The technological or other processes are done automatically, whereby the operator ensures only the start 
and controls the execution. The sequence of the workplace is set by a designated worker.

\section{Zonal and spatial aspects of designing production systems}

Creation of production systems is based on solving the functional and spatial relations of production technology. This is done by drafting the layout, or the spatial solution. When examining the functional and spatial layout of production systems, it is effective to divide space into zones and sub-zones. In terms of the zone hierarchy, ensuring complex technological processing requires that the initial, main and finishing technological operations are usually carried out at the workplace. Due to the differences in the technological methods and structures used in the initial, main and finishing technological processing, the functional structure of the complex workplace can be divided into its respective parts. The division into three parts is significant $[1,4,7]$ :

1. The Preliminary Technological Processing Workplace part, where the manufacturing and handling bases for the follow-up operations are generally prepared and the damaged layer of material is removed in the process of manufacturing the semi-finished products.

2. The Main Technological Process Workplace part, where most technological operations are carried out. It usually consists of several technological workstations with different functional structures.

3. The Special Technological Processes Workplace part, where the qualitative offset types of technological operations, required to complete the production (e.g. induction hardening, product cleaning, labelling, etc.), are performed.
On closer examination, it seems useful to analyze technological workstations as functional and spatial zones (Fig. 1):

- The technological zone is the area in which the technological operations on the products are carried out.

- The handling zone is the area in which handling (operational and inter-operational) of products, tools and waste, is performed,

- The control zone is the area in which the control operations are carried out,

- The operating zone is the area where adjustment, maintenance, repairs, etc. are done.

The nature of control operations is such that the control zone essentially coincides with the area occupied by the control elements of the workplace. A more detailed analysis should focus on the issues of the technology and handling zones of the workplace. For the purpose of designing, it is especially important to identify the quantitative parameters of the zones. The basic functional zone identifiers are $[5,6]$ :

- The shape of a zone, derived from the functional elements of the workplace, especially from the kinematic relations of the working mechanisms and units.

- The dimensions of the zone derived from the size of the functional elements and from the kinematics.

- Zone orientation referenced to the set base of workplace elements,

- Elemental zone structure expressed through the composition of partial zones.

For zone synthesis in workstations, it is especially important to optimize the relations of technological and handling zones for components

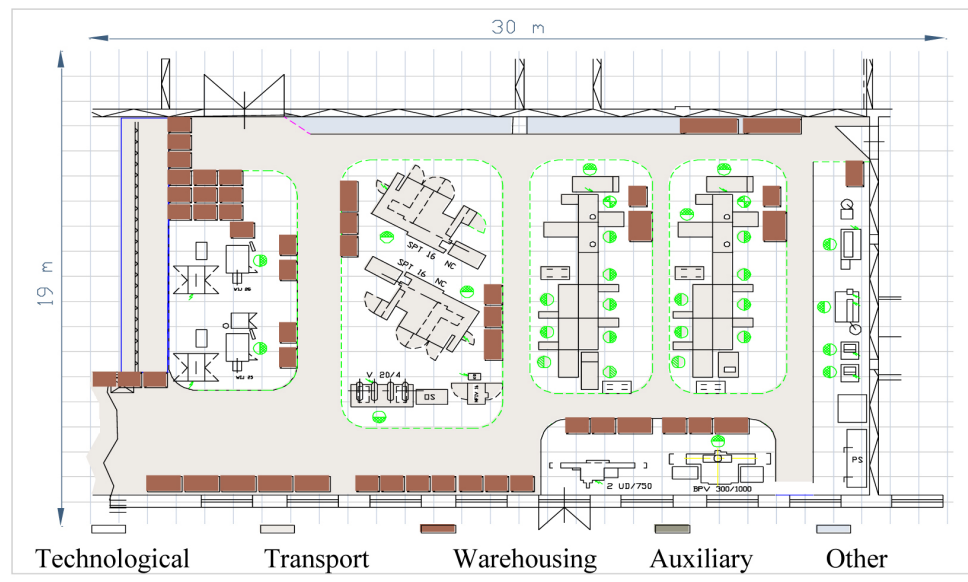

Fig. 1. Definition of production system zones 
that are functionally linked to the manufacturing process. The following is required:

- High degree of overlap of technological and handling zones. This condition minimizes the work space.

- Elimination of the "dead zones", that is, the parts of the technological zone that are not functionally available to the handling device. This condition increases the degree of workplace automation.

- Ergonomics of the man-operated zones.

- Compliant alignment of the shape, dimension and orientation properties of the handling and technological equipment zones.
After the individual building elements of the construction system have been analyzed in designing, the following step is the zone synthesis. The handling and technological zone synthesis is important in terms of efficient functional activities of the production system building elements. Consistency must be first achieved between the operational activities of handling and technological elements [9]. The individual zone synthesis does not only involve determining the size of their overlaps but also in the degree of their utilization. It is necessary to maximize the use of the zones with the minimized area occupied by the production system. The synthesis of
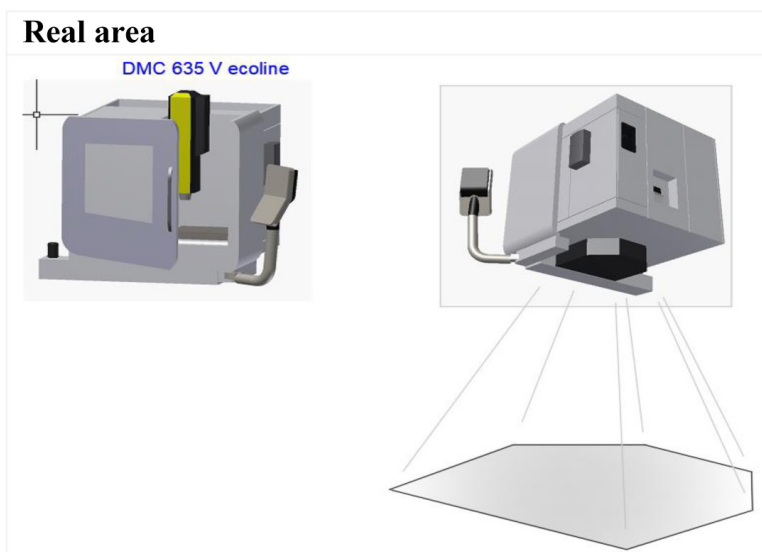

Theoretical area of the production equipment
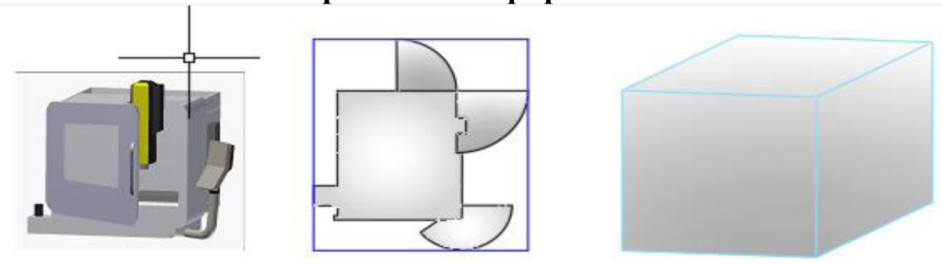

\section{Unused area}
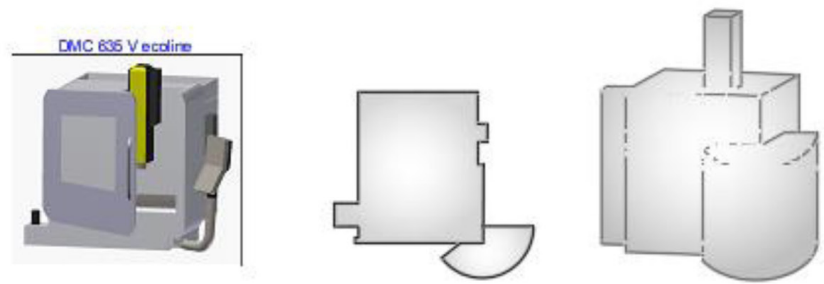

\section{Machine operator area}
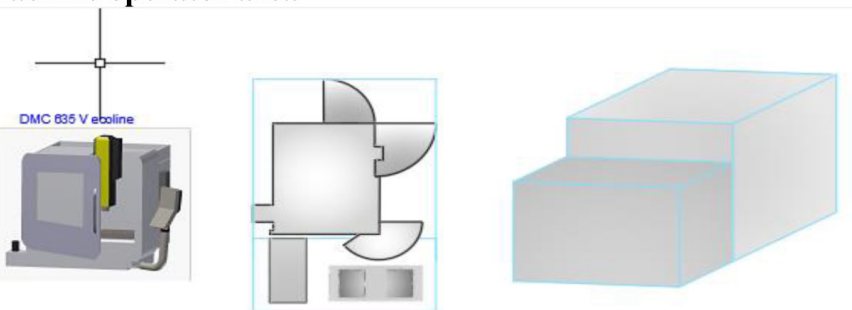

Fig. 2. Individual building elements of the construction system 
individual zones is preferably solved graphically, indicating the availability and the overlap of the elemental zones. The synthesis results are used in the processing of technological layout, which uniquely determines all elements and their spatial arrangement.

The quantitative and qualitative assessment of zone synthesis of individual production system building components can be accomplished in several ways. In addressing zonal problems, it is necessary to minimize the mounting surfaces, transport costs, eliminate the dead zones as well as achieve a high degree of the technological and handling zone overlap. It is also necessary to maintain safe distances and ergonomics of the human-operated zones $[2,8]$.

If we compare the sizes of each area type, the following applies:

$$
P_{S P}<P_{N P}<P_{T P}<P_{O P}
$$

Where:

$$
\mathrm{P}_{\mathrm{OP}}=\Sigma \mathrm{P}_{\mathrm{SP}}+\mathrm{P}_{\mathrm{NP}}+\mathrm{P}_{\mathrm{TP}}
$$

The examples of the elemental area types of workplace production zones are as follows:

\section{Elemental area " $A$ ":}

- delimited by lines parallel to: " $\mathrm{O}_{\mathrm{x}-}$ oy “"

- the following holds for the elemental area:

$$
y_{1} \leq y \leq y_{2} \quad x_{1} \leq x \leq x_{2}
$$

- area size:

$$
P=\iint_{Z} d x d y=\int_{x_{1}}^{x_{2}} \int_{y_{1}}^{y_{2}} d y d x=\left(x_{2}-x_{1}\right) \cdot\left(y_{2}-y_{1}\right)
$$

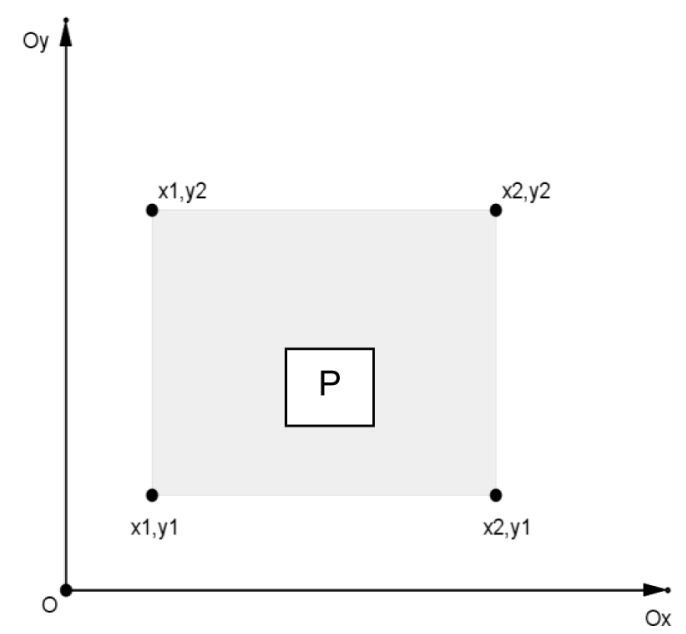

Fig. 3. Elemental area types of workplace production zone "A"

\section{Elemental area " $B$ ":}

- delimited by lines parallel to "

- the following holds for the el-

$$
\begin{array}{lr}
\text { emental } & \text { area: } \quad \begin{aligned}
x_{1} & \leq x \leq x_{2} \\
y_{3} \leq y \leq f\left(x_{j}\right), & \text { or } \quad f\left(x_{j}\right) \leq y \leq y_{3}
\end{aligned} \\
f\left(x_{j}\right)=\frac{y_{2}-y_{1}}{x_{2}-x_{1}} x+\frac{x_{2} y_{1}-x_{1} y_{2}}{x_{2}-x_{1}} &
\end{array}
$$

- area size

$$
\begin{gathered}
P=\left|\iint_{Z} d x d y\right|=\left|\int_{x_{1}}^{x_{2}} \int_{y_{3}}^{\frac{y_{2}-y_{1}}{x_{2}-x_{1}} x+\frac{x_{2} y_{1}-x_{1} y_{2}}{x_{2}-x_{1}}} d y d x\right|= \\
=\left|\frac{\left(x_{2}-x_{1}\right)\left(y_{1}+y_{2}\right)}{2}-y_{3}\left(x_{2}-x_{1}\right)\right|
\end{gathered}
$$

\section{Elemental area " $\mathrm{C}$ ":}

- delimited by lines - independent of $\mathrm{O}_{\mathrm{x}}$

- the following holds for the elemental area: $x_{1} \leq x \leq x_{2} \quad f\left(x_{i}\right) \leq y \leq f\left(x_{j}\right)$, where

$$
\begin{aligned}
& f\left(x_{i}\right)=\frac{y_{2}-y_{1}}{x_{2}-x_{1}} x+\frac{x_{2} y_{1}-x_{1} y_{2}}{x_{2}-x_{1}}, \\
& f\left(x_{j}\right)=\frac{y_{4}-y_{3}}{x_{2}-x_{1}} x+\frac{x_{2} y_{3}-x_{1} y_{4}}{x_{2}-x_{1}} .
\end{aligned}
$$

- area size

$$
\begin{array}{r}
P=\iint_{Z} d x d y=\int_{x_{1}}^{x_{2}-y_{1}} \int_{\frac{y_{2}}{x_{2}-x_{1}}}^{\frac{y_{4}-y_{3}}{x_{2}-x_{1}}+\frac{x_{2} y_{1}-x_{1} y_{2}}{x_{2}-x_{1}}} d y d x= \\
=\frac{\left(x_{2}-x_{1}\right)\left(y_{4}+y_{3}-y_{2}-y_{1}\right)}{2}
\end{array}
$$

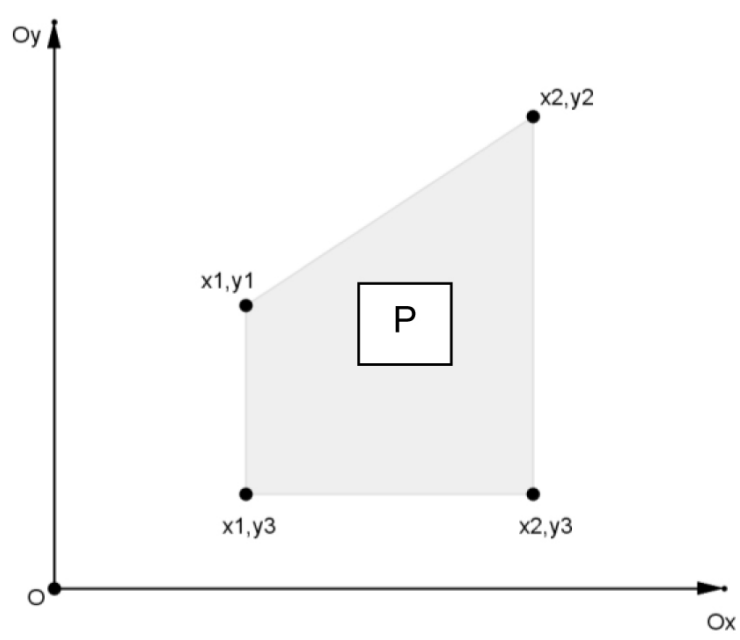

Figure 4. Elemental area types of workplace production zone "B" 


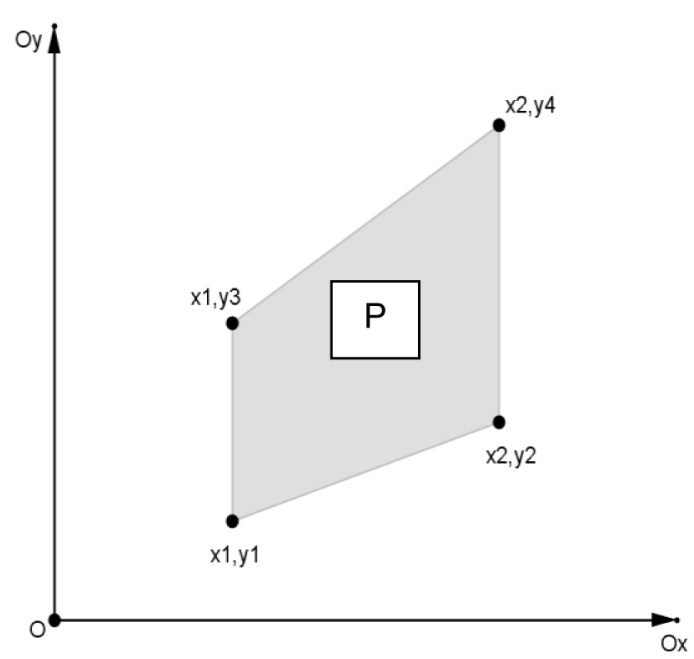

Fig. 5. Elemental area types of workplace production zone "C"

\section{Elemental area " $D$ ":}

- delimited by a line parallel to the polynomial $\mathrm{O}_{\mathrm{x}}$, of the n-th power (e.g., second order polynomial)

- the following holds for the elemental area: $x_{1} \leq x \leq x_{2} \quad y_{1} \leq y \leq a_{2} x^{2}+a_{1} x+a_{0}$

- area size:

$$
\begin{gathered}
P=\iint_{Z} d x d y=\int_{x_{1}}^{x_{2} a_{2} x^{2}+a_{1} x+a_{0}} \int_{y_{1}} d y d x= \\
=\frac{a_{2}}{3}\left(x_{2}{ }^{3}-x_{1}^{3}\right)+\frac{a_{1}}{3}\left(x_{2}{ }^{2}-x_{1}{ }^{2}\right)+\left(a_{0}-y_{1}\right) \cdot\left(x_{2}-x_{1}\right)
\end{gathered}
$$

\section{Elemental area " $E$ "}

- delimited by a circle or part of a circle. For the elements working in other than a rectangular coordinate system, transformation into polar coordinates may be applied:

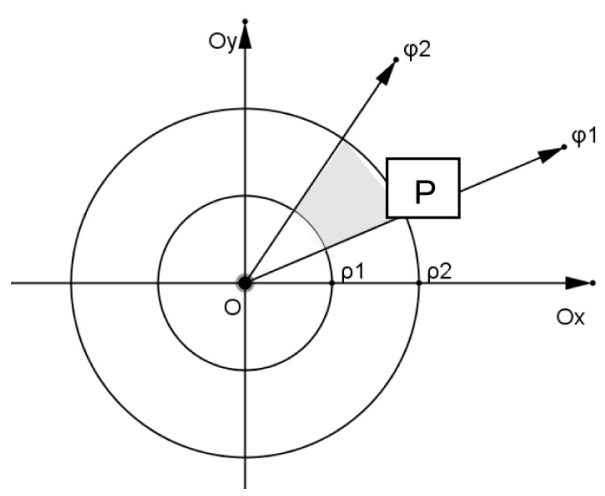

Fig. 7. Elemental area types of workplace production zone "E"

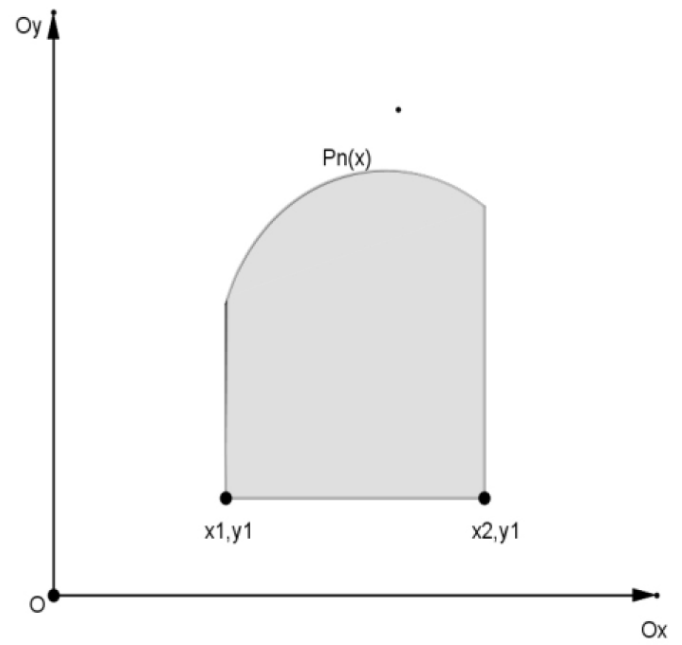

Figure 6. Elemental area types of workplace production zone " $D$ "

- $\rho, \varphi,(0 \leq \rho \leq \infty, 0 \leq \varphi \leq 2 \pi)$.

- the following holds for the elemental area: $\rho_{1} \leq \rho \leq \rho_{2} \quad \varphi_{1} \leq \varphi \leq \varphi_{2}$

- area size

$P=\iint_{Z} \rho d \rho d \varphi=\int_{\varphi_{1} \rho_{1}}^{\varphi_{2} \rho_{1}} \rho d \rho d \varphi=\frac{\left(\rho_{2}^{2}-\rho_{1}^{2}\right)\left(\varphi_{2}-\varphi_{1}\right)}{2}$

In order to determine spatial characteristics of each type of the area built up by the production equipment, the following also holds (Table 1):

\section{Production systems layout}

Designing activity output consists in processing of the technological layout of workstations and production systems in such a way that uniquely determines the constituents of production and their spatial arrangement. The basic tasks in solving the layout of production equipment include determining spatial relations between the means of production, the products and the human - operator. It is necessary to determine which of these elements have a fixed place and how this place is determined. On the basis of the combination, the basic variants of the workspace arrangement are created $[1,10]$ :

- The means of production and the operator have a fixed place. This case is typical for most of the workstations in engineering production.

- All workplace elements are fixed. This is the case when all operations are performed on one machine. The examples of this arrangement are workstations with NC-machining centers and automatic machines. 
Table 1. Mathematical description of the calculation of space requirements of the projected production equipment

\begin{tabular}{|c|c|c|}
\hline Area type & Type of premises & Area size \\
\hline Real space & type A - C & $P=P_{A}+P_{C}=\iint_{Z_{A}} d x d y+\iint_{Z_{C}} d x d y$ \\
\hline $\begin{array}{c}\text { Theoretical } \\
\text { space }\end{array}$ & type A - D - E & $\begin{array}{l}P=P_{A 1}+P_{A 2}+P_{A 3}+P_{D}+P_{E 1}+P_{E 2}+P_{E 3}+P_{E 4}= \\
P=\iint_{Z_{A 1}} d x d y+\iint_{Z_{A 2}} d x d y+\iint_{Z_{A 3}} d x d y+\iint_{Z_{D}} d x d y+ \\
+\iint_{Z_{E 1}} \rho d \rho d \varphi+\iint_{Z_{E 2}} \rho d \rho d \varphi+\iint_{Z_{E 3}} \rho d \rho d \varphi+\iint_{Z_{E 4}} \rho d \rho d \varphi\end{array}$ \\
\hline $\begin{array}{l}\text { Nonusable } \\
\text { space }\end{array}$ & type A - D - E & $\begin{aligned} P= & P_{A 1}+P_{A 2}+P_{A 3}+P_{A 4}+P_{A 5}+P_{D}+P_{E 1}+P_{E 2}= \\
P= & \iint_{Z_{A 1}} d x d y+\iint_{Z_{A 2}} d x d y+\iint_{Z_{A 3}} d x d y++\iint_{Z_{A 4}} d x d y+\iint_{Z_{A 5}} d x d y+ \\
& +\iint_{Z_{D}} d x d y++\iint_{Z_{E 1}} \rho d \rho d \varphi+\iint_{Z_{E 2}} \rho d \rho d \varphi\end{aligned}$ \\
\hline $\begin{array}{l}\text { Operator } \\
\text { space }\end{array}$ & type A-B- D - E & $\begin{aligned} P= & P_{A 1}+P_{A 2}+P_{A 3}+P_{A 4}+P_{B}+P_{D}+P_{E 1}+P_{E 2}= \\
P= & \iint_{Z_{A 1}} d x d y+\iint_{Z_{A 2}} d x d y+\iint_{Z_{A 3}} d x d y++\iint_{Z_{A 4}} d x d y+\iint_{Z_{B}} d x d y+ \\
& +\iint_{Z_{D}} d x d y++\iint_{Z_{E 1}} \rho d \rho d \varphi+\iint_{Z_{E 2}} \rho d \rho d \varphi\end{aligned}$ \\
\hline
\end{tabular}

- Only the production equipment has a fixed place (workstations with multi-tool operation).

- The production equipment and products have a fixed place (multi-tool operation of NC-machining centers and automatic machines).

- Only the worker has a fixed place (a unique case of machine carousels, where several machines are rotating on a rotating plate).

- Only the product has a fixed place (production of heavy, large-sized objects).

- The product and the operator(s) have a fixed place.

- All workplace elements are mobile.

Among the basic variants of the technological workplace layouts, variants 1 (single-operator operation) and variant 3 (multi-tool operation) are the most common in the machine-building industry. The spatial arrangement of production equipment at the workplace is influenced by several factors. The most important of these are:

- Minimal transport routes.

- Minimal storage and auxiliary areas.

- Convenient handling operations.

- Respecting the basic conditions of the structure (power lines, lighting, floor load capacity, etc.).

Commonly used arrangements are as follows: Arrangement in the line. This variant is advantageous in terms of a simpler solution of the traffic roads and power distribution, and it is most often used in practice.

Arrangement into a polygon (circle): This way, the handling flow and the work area are reduced in a direct continuity of the production on individual machines. The disadvantages of this solution involve a more complicated for installation and access to the workplace during setup and maintenance.

Combination of linear and polygon layout: In this case, special methods are used, the essence which is compiling the layout variants and optimal variant selection according to the selected criteria.

When designing dispositive production arrangement, it is necessary to keep certain minimal distances between individual production facilities and fixed elements of building constructions (e.g. columns, walls, etc.). The minimal distances depend in particular on:

- Type and function of manufacturing equipment,

- Dimensions of the materials being handled,

- Mutual position of devices and the organization of handling,

- Energy and safety factors of devices.

Various special methods have been developed to solve the deployment problems. The essence of these methods is compiling the layout 
variants and optimal variant selection according to the selected criteria. Raster network types as auxiliary graphical tools play a major role in designing manufacturing system layouts. The use of industrial rasters is especially advantageous in relation to the design of production activity. These are planar or spatial lattices formed by parallel perpendicularly intersected straight lines (raster lines), the mutual spacing of which is standardized. Industrial rasters enable to create direct dimensional relations between the given space and the elements of production system placed therein. Part of these can be single modules of industrial buildings standardized halls.

In addition to industrial raster with its perpendicularly intersected straight lines, other types of rasterization, - for example, a triangular raster are also used in design. The basic or preselected dimensions of the space are the starting point for determining the industrial raster. They are based on the modules as basic units of a particular dimensional system. The dimension of raster, which is to be the basis for the reference space and, at the same time, for the design of the system, is a multiple or share of the $M 100 \mathrm{~mm}$ module used in practice $[3,5,7]$.

It is also advantageous to use the industrial raster for making a layout of an industrial area or an industrial complex (Fig. 8). It is the basic graphic tool for dividing the given space (territory). It creates the prerequisite for an optimal assembly halls integration with the area available.

In new designs, defining the position of the boundary lines, columns, etc. is helpful in facilitating the arrangement of the means of production. According to the raster network, it is possible to distribute not only the technical equipment but also its installation. In order to optimize the layout of the construction elements of the production system, the spatial relations between the technical and handling zones are particularly important.

\section{Selected methodological aspects of designing robotic system structures}

In general, there is a fundamental difference between creating simple robotic modules and cells and creating higher-type robotic production clusters. Detailed structural analyses are emphasized in complex clusters that have to take into account especially the following aspects:

- The number of production objects that pass through individual workstations at a defined time,

- The number of production machines, robots and other equipment integrated into one production cluster, limited by their downtime,

- Problems of priority executing technological and handling operations in a production cluster.

- Variant methods of generating production cluster structures.

The importance of structural analysis is related to the influence of the structure on the characteristic indicators of the system quality. In particular, the structure affects the flexibility of the system expressed by the ability to respond quickly to the changes in the vicinity of the system in accordance with the target function. The flexibility of the system depends on the number of elements and the manner of their interconnection.

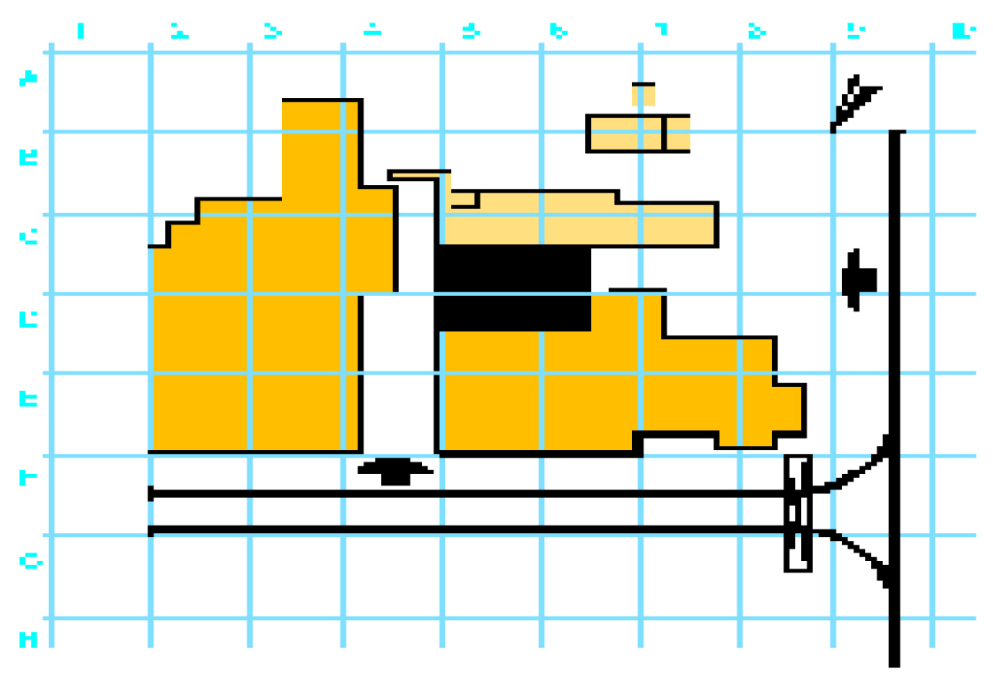

Fig. 8. Gross raster of the production area 
The shorter the distance and the fewer the links between the elements, the shorter the reaction time for the external action characterizing the system's flexibility. Extreme system flexibility is usually unnecessary, as the system then responds to weak external stimuli and becomes overloaded in consequence. Increasing the number of links (multi-link structure) raises the system costs.

An important characteristic of the system structure is the manoeuvrability, which is quantitatively evaluated by the median number of links between the elements. The higher this indicator, the better the system can be controlled. By increasing the degree of manoeuvrability, independence of the elements and subsystems increases, too. The manoeuvrability is important if the system elements are to be capable of development and specialization.

Another characteristic of the structure is the element centralization, which is closely related to manoeuvrability. In a system designated to work in a fixed defined mode, maximum centralization of the elements is an advantage. For multi-purpose flexible systems, the degree of centralization according to functional designation should be selected $[8,9]$ ::

The structure also influences the reliability of a system that depends on the number of elements and links and on the functional characteristics of a system that do not fall below the specified limits when they are damaged. The current practice is characterized by a large variation of robotic system structures. In addition to the above-mentioned sources of variability derived from the level of clustering, internal modules and cells variability factor in as well. The main influence on the internal structure of robotic modules and cells involves:

- The degree of function concentration,

- The manner of functional interconnection of the main elements,

- The spatial situation of the main elements.

Differentiation and concentration of function is reflected in:

a) Production machines in single-operator and multi-operator systems,

b) Robots in the systems:

- One-arm robot with a gripper.

- Application of multiple grippers.

- Application of multi-arm robots.

- Application of several robots at one Workstation. c) Input-output devices:

- An integrated input / output device.

- Divided input and output.

- Single and multi-position (palletizing) workstations.

From a general point of view, the structures based on differentiation of functions are less demanding technically, operationally and economically. Function concentration increases producibility, flexibility, production quality and saves production area. The development trends throughout the production processes are based on increasing the function concentration.

Functional interconnection of the main elements of robotic systems is derived from the flow of material and information. The following are distinguished:

1. Firm structure of functional activities - the system layout clearly defines the technological and handling operations and various combinations thereof.

2. Free structure of functional activities - system layout enables mutually independent technological and handling operations and various combinations thereof.

3. Combined structure of functional activities (Fig. 9).

An important parameter that influences the decision on the choice of the robotic system structure for a given production task is defining the specialization of the manufacturing operations. The indicator of the level of specialization is expressed by the relation:

$$
k_{S}=\frac{\sum_{i=1}^{n} C_{i} \cdot G}{\sum_{j=1}^{m} S_{j}}
$$

where: $S j$ - theoretical producibility of technological and handling units (components, operations),

$G$-number of settings (available program changes),

$C i$ - number of operations (components) executed with one setting (program), $m$ - number of main system elements, $n$ - number of operations (components) performed in one cluster.

The specialization level indicator synthesizes a considerable number of factors (structural, technological, static, dynamic) that determine 


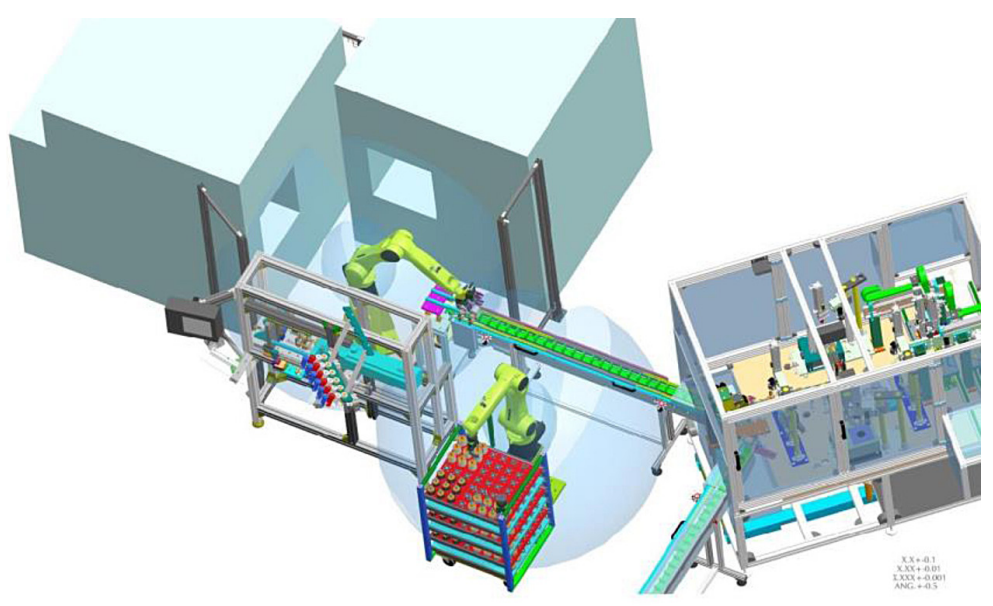

Fig. 9. An example of a configuration solution for a robotized production cel

the degree of flexibility (mobility) and the degree of stability of the production conditions. For the value of $\mathrm{pc} \leq 1$ systems are specialized at the level of mass production, $\mathrm{pc}=2$ to 4 large series, $\mathrm{pc}=$ 5 to 22 series and $\mathrm{pc}>23$ small series production.

Robotic modules and the cells characterized by increased levels of technological readiness derived from program management also have sufficient stability of the production conditions, which corresponds to the level of specialization $p c=5$ to 15. For this indicator of the level of specialization, the basis of the functional activity is the group technology.

Group handling is important in robotic modules and cells. The group handling procedure is a set of handling operations that use one robot (several robots) that has a grouped gripper controlled by a group program. The specific handling procedures in a group differ by sequencing cycle completeness and by corrections of spatial point positions $[1,11]$.

The number of basic technological units and robots in the systems with group technology and handling is determined in calculation of their capacity. It is possible to draw on the technological $\mathrm{kt}$ and handling $\mathrm{km}$ coefficients of middle to relatively labor intensive group production procedure:

$$
k t=\frac{\sum_{i=1}^{k t o i} t i j}{k t o i \times \tau t i} \quad k m=\frac{\sum_{i=1}^{k m o i} t i j}{k m o i \times \tau t m i}
$$

where: $k_{\text {toi }}-$ the number of technological, or handling operations of the $i$-group procedure, $t_{t i j}$ - duration of the $j$-operation, the $i$-technological, or handling procedure, $t_{\text {tij }}-$ the cycle of the $i$-group procedure.
When the robotic system structure has been resolved, the multi-operator service demands closer attention. The organizational prerequisites of multi-operator service are: rational machine alignment to ensure short distances between machines, automatic production quality control and the relatedness of the size and shape of the objects handled. Generally, a cyclical and a non-cyclical manner of multi-operator service is distinguished. During the cyclical multi-operator service, the time of the cycle Tc equals to the sum of the free machine time $T s$ and the operating time of the machine $T o$. The number of machines in service can be calculated from the following relation:

$$
\mathrm{n}=T_{s} / T_{o}+1
$$

During the non-cyclical multi-tool operation, there are the cases where the technological process has been terminated on one or more machines in operation while the robot is still operating on another machine. The machines wait for certain time for the operator. The total cycle time of the operation can be calculated from the following relation:

$$
T c=T s+T o+T c
$$

where: $T c$ is downtime due to waiting for the operator.

The idle time values from waiting for the operator can be determined by statistical measurement of downtime or analytically, using the theory of mass operation. If the machines in operation do not run according to the general rhythm of work, then cyclical operation can be used when the same technological operation is performed on all machines in operation, or when the operation time of each machine is approximately the same. In robotic systems, cyclical operations are usually 
less economically beneficial due to the different nomenclature of the manufactured objects processed. The machine time differences increase the working time considerably. The operation cycle can be simple when every machine operates in a cycle once only, or complicated when the machine operates like that several times.

Cyclical operation can be used if Tmax/Tstr $\geq \mathrm{K}$, where Tmax is the maximum machine time, Tstr - average machine time on the machines in operation, $K$ - overlapping operation coefficient. An example of production cell with a robot cooperating with a human is shown in Figure 10.

\section{Selected methodical aspects of designing production lines}

The basic principle related to designing production lines is the current nature of production. In the case of stream production, technological operations are always assigned to certain devices. The production facilities are deployed in a series of operations and the object of production (component, product) proceeds from one operation to another one by a special conveyance system production lines are resolved as:

- Single-purpose lines - for the technological processing of one product type.

- Combined lines - for the technological processing of identical products.

- Group-processing lines - for the technological processing of different products of a given group.

The production lines that include various types of technological processing (shaping, machining, heat treatment, assembly, etc.) are referred to as complex lines. The starting point for line designing is the calculation of the production cycle. The production cycle (tt) is the time period during which the technological processing of the product is completed on the line. It is calculated from the relation:

$$
t t=T / Q
$$

where: $T$ - time available,

$Q$ - required number of products per time $T$.

From the required cycle, the number of individual $\left({ }_{i}\right)$ production facilities ni is calculated:

$$
n i=t o i / t t
$$

where: toi - operating time on $i$ production facilities.

Since the technological times generally do not correspond to the production line cycles, no absolute line synchronization or high machine utilization can be achieved. However, this is not necessary. If only high utilization facilities, which ensure synchronicity of operations, are selected when designing production lines at the expense of maximum efficiency, the overall effect will be negative. In the case of production lines, production cycle time $T c$ equals the labor intensity of the product manufacturing process:

$$
T c=t t \cdot p
$$

where: $t t$-cycle of production line,

$$
\begin{aligned}
& p \text { - number of operations required to } \\
& \text { make the product. }
\end{aligned}
$$

When designing production lines, it is also necessary to calculate the backlogs of the production:

$$
R=\sum_{i=1}^{p} s_{i}+\frac{1}{t_{i}}\left(\sum_{i=1}^{p} T_{n i}+2 T_{z}\right)
$$

where: $p$-number of jobs on the line,

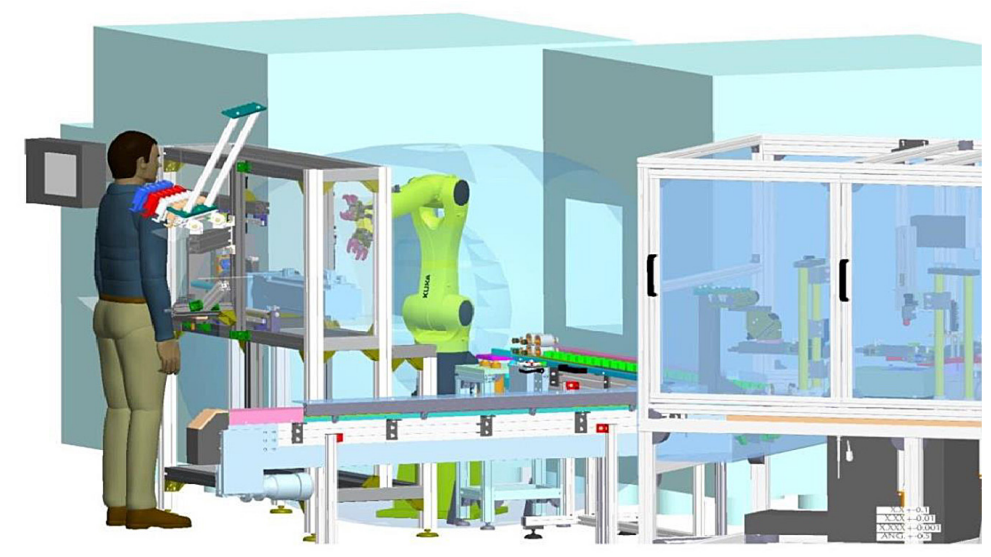

Fig. 10. Illustration of a "man-robot" hybrid production cell 
$S i$ - number of currently manufactured components (products) at a given $\mathrm{i}$ workstation, $t_{t}$ - production line cycle, $T_{n i}-$ time needed to set up a job (tool change, waste removal, etc.),

$T_{t}$ - time at which the line is to be aligned with the semi-finished or finished products.

\section{CONCLUSIONS}

In case of insufficient production backlogs, unpredicted downtimes of subsequent workstations may occur. In order to reduce the downtime losses, automatic trays with spare components are incorporated into automated lines. The condition for introducing automatic production lines is a sufficient production volume. Therefore, in designing, the minimal and optimal production volume is calculated analytically.

The basis for the calculation is the comparison of the production costs and costs of automatic production line implementation. In the automated lines, different types of roller conveyors, slip conveyors, troughs, carts, conveyors, platforms, tables, belt conveyors and other equipment is used to guide the traffic between operations. The traffic devices are often combined with preparations. The roller conveyor then leads to the point of placing the component into preparation. This reduces the clamping time to minimum.

\section{Acknowledgement}

This work has been supported by the Scientific Grant Agency of the Ministry of Education of the Slovak Republic (KEGA 026EU-4/2018) and the Scientific Grant Agency of the Ministry of Education of the Slovak Republic (VEGA 1/0376/17).

\section{REFERENCES}

1. Daneshjo, N., Majernik, M., Dudaš Pajerská, E. Danishjoo, M.: Methodological Aspects of Modelling and Simulation of Robotized Workstations. TEM Journal, 2, 2018, 293-300.

2. Daneshjo, N., Rudy, V., Repková, K., Mareš, A., Kováč, J., Jahnátek, J., Krivosudská, J., Šmajda, N., Rusnák, J.: Intelligent industrial engineering - Innovation potential. FedEx Print \& Ship Center, USA, 2018.

3. Buckova M., Krajcovic M., Edl M.: Computer simulation and optimization of transport distances of order picking processes. Procedia Engineering, 192, 2017, 69-74

4. Kovač, J., Rudy, V., Kováč, J.: Methods for the design of production processes. Specifics of designing production systems. Edition of Professional and Scientific Literature, 2017.

5. Plinta, D., Krajcovic M.: Production system designing with the use of digital factory and augmented reality Technologies. Advances in intelligent systems and computing. 350, 2016, 187-196.

6. Bubeník, P., Bubeníková, E., Korbel, P., Nagy, P.: Information Technology for Business Practice. Edis, ŽU in Žilina, 2004.

7. Wiendahl, H., P., Reichardt, J., Nyhuis, P.: Handbook Factory Planing. Springer-Verlag Berlin Heidelberg, 2015.

8. Hammer, M.: The Superefficient Company. Harvard Business Review, 9, 2001, 84-92.

9. Micieta, B., Edl, M., Krajcovic, M., Dulina, L., Bubenik, P., Durica, L., Binasova, V.: Delegate MASs for coordination and control of one-directional AGV systems: a proof-of-concept. The International Journal of Advanced Manufacturing Technology, 94, 2018.

10. Monczka, Robert M. and Jim Morgan: What's Wrong with Supply Chain Management? Purchasing, 1, 1997, 69-72.

11. Cooper, M., C., Douglas M. Lambert, Janus D., Supply Chain Management: More than a New Name for Logistics. The International Journal of Logistics Management, 1, 1997, 1-14. 